scientific officers (sometimes both). Professor Whitby's distinction between "PTA scientists" and the most senior MLSOs is indeed totally artificial.

Professor Whitby and Dr Sewell object to the "multidisciplinary" principal MLSO. Their real worry is not scientific ability, however, but laboratory management-a quite separatc skill. The Association of Clinical Pathologists has recently said ${ }^{2}$ that "there are few recently trained pathologists, graduate scientists, or medical laboratory scientific officers who can competently practise more than one of the four main disciplines of pathology." What is sauce for the goose is sauce for the gander. If pathologists, "graduated scientists," and MLSOs all no longer receive multidisciplinary training, then no one group is more or less suited than the others for multidisciplinary management, and additional possession of a qualification in management becomes more significant than the disciplines which an individual has or has not practised in the laboratory.

The nub of the matter is the acceptance by all concerned that laboratories may be managed by "non-medical scientists." After (say) 25 years of laboratory experience a $\mathbf{P h D}$ holder either is or is not of the calibre to head a department. Whether he is employed under the conditions of Whitley Council PTA or PTB is of no relevance.

Perhaps a less antagonistic attitude on the part of some individuals would do more to achieve harmony in the medical laboratory than would vain attempts to justify attitudes which seem to owe more to élitist prejudice than to reason.

A D FARR

Lumphanan, Aberdeenshire

'Association of Commonwealth Universities. Compendium of university entrance requirements. London Association of Commonwealth Universities, 1980. Association of Clinical Pathologists. ACP Nervs
Spring 1981:3.

November 12: col 201 .

\section{The changing face of the laboratory}

SIR,-It is interesting, and perhaps significant, that your debate on the future of pathology and the role of pathologists should be introduced by a principal medical laboratory scientific officer. Mr J B Burns makes several important comments but these seem to stand in isolation from or even in contradiction to the main thrust of his article (13 June, p 1943).

Mr Burns makes generalisations from exceptions. He says that "Specialist surgeons wish to examine their biopsy specimens during the operationsay, in a convenient side room. Why should they have to send them to someone else?" This is irrelevant to the bulk of routine histological work. Most surgeons are only too happy to send their material to "someone else."

Although working in the same region as $\mathrm{Mr}$ Burns I am not persuaded that "the modern training curricula of medical students in a hightechnology medical school environment enables them to assess laboratory information and draw conclusions without help." On the contrary, my first-hand experience is that they need considerable help, if only to lessen their dependence on so-called high-technology and use a little common and clinical sense instead.

The statement that "If the demands of acute medicine and surgery cannot be met as they are in the private sector then hospital pathologists will have only themselves to blame for their inadequacy" makes difficult reading, possibly owing to a weakness in grammar or logic.
These disparate statements seem to be a shaky platform for Mr Burns's attempt to advise "th royal college and the association" (presumably the reference is to the Royal College of Pathologist and the Association of Clinical Pathologists) on the future role of pathologists. When I read M Burns's article I had just seen Sir Melville Arnott's contribution to the June Bulletin of the Roya College of Pathologists. ${ }^{1}$ This highlights the rea nature of the problem, which has now become crisis. The problem to those pathologists who are facing heavy service demands is not whether we should "take over a functional middle-managemen administrative role." Far too much time is bein wasted and ill feeling engendered by talking abou "who does what." The real crisis is a critical shortage of pathologists in many district hospitals. This applies particularly to histopathology. Before there can be any increase of staff in other clinica disciplines, there must in every district genera hospital be at least two pathologists who can provide mutual cover in histopathology. Si Melville Arnott emphasises that the demand for adequate staffing in pathology must come from the clinicians who require a high standard of pathological services. I can assure Mr Burns that those pathologists who are facing increasing work loads have no problem as regards "any remaining clinical raison d'être for their discipline."

The criticism that ought to be directed at the organisation of pathology has not been made-namely, that we are now reaping what has been sown. The ridiculous claim that eight consultants should cover the four subdisciplines in every district general hospital encouraged an increasing degree of demarcation between the specialists in these disciplines -so that even given four consultants in one average hospital these may be unable to provide mutual cover. The paradox is that whereas there is undeniably a need for more specialisation in certain areas there is also a parallel requirement for less rigid demarcation in others. For this reason I should certainly support Mr Burns's plea for more flexibility in planning and manning laboratory services. We might even rediscover what used to be called a clinical pathologist.

D E B Powel

Bridgend General Hospital,

Bridgend, Mid Glam CF31 1JP

' Arnott M. Bull R Coll Pathol 1981 ;No 35 :1-4.

SIR,-It is apparent to me that by publishing the article by Mr J B Burns (13 June, p 1943) on the redundancy of pathologists you are contributing towards the staffing crisis in that specialty, as many of my older colleagues worn down by years of coroners' postmortem examinations and port drinking will surely have died of apoplexy. As one who has survived and intends to remain in charge of his laboratory, I would like to introduce a few arguments in favour of our continued employment, though it must be stressed that in the best tradition of such "debate" I will make no attempt to answer any of the points raised by Mr Burns.

The idea that the clinical user of laboratory services does not need any interpretation of their results may have been true for a limited number of physicians and surgeons training 40 years ago, when the range of tests was limited and the joint appointment of physician and pathologist was commonplace; but in recent years it has been difficult to arrange for clinicians in training to have even six months in the laboratory and I know of no general practitioner trainee scheme that incorporates formal laboratory training. Without such training one is in the invidious position of having to accept results uncritically, and that is naive and dangerous. If the clinician needs the pathologist so does the laboratory. By virtue of his status the pathologist should be in a position to speak on behalf of the laboratory within the medical and administrative echelon, to argue for his share of money and staff and to act as a foil when unreasonable demands are made on the laboratory. It is also incumbent on those of us who are clinicians as well as pathologists to give our staff the opportunity of seeing patients as well as test tubes full of blood; and for my own part I am happy to run my clinics and haemophilia service within the laboratory complex, rather than succumb to the charms of a new outpatient department in another hospital, so that we can all relate to patients-and trip over them if we try to get off to coffee in the middle of a clinic.

If the pathologist is not in charge of his laboratory he cannot be responsible for the work performed by that laboratory or for the morale of his non-medically qualfied colleagues; and those who are constantly trying to erode the position of the pathologist must realise that, should they succeed, the status of the laboratory within the hospital may well suffer.

Michael McEvoy

Department of Pathology,

Harrogate General Hospital,
Harrogate, N Yorks HG2 7ND

\section{A centre of excellence in Africa}

SIR,-Situated here in Zimbabwe where there is tremendous change going on, I am always very interested in the thoughts expressed in your series on student electives. I was most interested in one by Aysha Cockshott (21 February, p 636) from Cardiff, on the time she spent at the Kenyatta Hospital, the university hospital of Kenya in Nairobi. It prompts me to make a plea that students might consider coming a bit further south to us here in Salisbury, Zimbabwe, where there is an extremely modern and up-to-date hospitalthe Andrew Fleming Hospital-serving the needs of the Godfrey Huggins School of Medicine and also the multiracial patients, of whom at present there is a slight majority of whites. There is also an extremely well-run African hospital at Harare, which has an excellent reputation for the work and teaching available there. If anyone would be interested in coming to this country I should be delighted to do anything I could to help.

William Houston

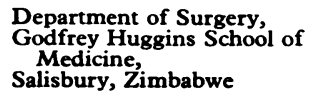
Medicin Salisbury, Zimbabwe

\section{Correction}

Pindolol acts as beta-adrenoceptor agonist in orthostatic hypotension

We regret that in the letter by Dr G Nyberg (23 May, $p$ 1704) an error occurred in the figure: the ordinate scale should start at 0 , not 20 . The address should read "MUC Laboratory, Department of Medicine. ...." 